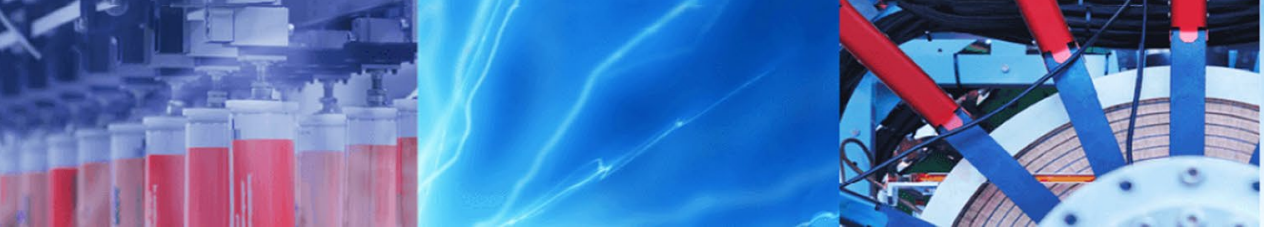

Research Article

\title{
Influence of slide burnishing process on the surface characteristics of precipitation hardenable steel
}

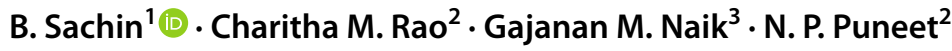

Received: 4 October 2020 / Accepted: 20 January 2021 / Published online: 27 January 2021

(C) The Author(s) 2021 OPEN

\begin{abstract}
The surface integrity of the material is the predominant necessity of a component to perform efficiently in varying working conditions. To improve the surface integrity of the workpiece secondary finishing processes are being performed. This work attempts to propose a realistic cryogenic slide burnishing condition for improvement of the surface integrity. The slide burnishing was performed by a novel slide burnishing tool on 17-4 precipitation hardenable stainless steel. The experiment was designed based on a central composite design. Initially, the effect of control parameters on the output response was examined by experimental analysis based on the design of experiment. Analysis of variance was used to analyze the influence of the variables on the performance indices. The regression technique was used to develop an empirical model. Optimization of process parameters for finding minimum surface roughness and maximum surface hardness was achieved by a multi-objective genetic algorithm. The optimized solutions were validated by performing confirmation experiments.
\end{abstract}

Keywords Novel slide burnishing tool · Optimization · Cryogenic · Slide burnishing · Surface integrity

\section{Introduction}

The surface properties and dimensional precision of the components are the two most crucial factors which are considered seriously in modern manufacturing industries. Burnishing is a superior super finishing technique in which a decent surface finish of the component can be attained easily. The slide burnishing process is one of the recent developments in the area of burnishing which has been utilized by most of the production industries to increase the surface integrity properties of the material. Diamond has been used at the tip of the stem of the tool which will deform the material. As the slide burnishing process is carried out, the diamond tip slides over the workpiece, and the mirror finish of the surface can be attained with a careful assortment of the process parameters. To enhance the effectiveness of the method, different kinds of lubricants have been used in industries [1]. Liquid nitrogen $\left(\mathrm{LN}_{2}\right)$ is one such coolant that has been efficiently used as a lubricant [2]. Some of the notable benefits of $\mathrm{LN}_{2}$ are: it is environment-friendly, and also it does not have much impact on the operator $[3,4]$. The functional properties of the material can be improved after performing a slide burnishing operation using $\mathrm{LN}_{2}$ as the coolant, and it has to be directed at the slide burnishing zone.

$\mathrm{PH}$ stainless steels are known for their excellent strength, high hardness, and corrosion resistance. Martensitic stainless steel such as 17-4 PH stainless steel finds application where intergranular and pitting corrosion resistance are not dominant factors. It is called difficult to cut material on account of its high ductility and low thermal conductivity [5]. Machining this steel is one of the

B. Sachin, sachinraobc@gmail.com | 'Department of Mechanical Engineering, The National Institute of Engineering, Mysuru, Karnataka 570008, India. ${ }^{2}$ Department of Mechanical Engineering, National Institute of Technology Karnataka, Surathkal 575025, India. ${ }^{3}$ Department of Mechanical Engineering, Mangalore Institute of Technology and Engineering, Moodabidre, Mangalore, Karnataka 574225, India. 
hectic tasks because of the generation of high temperatures at the tool-workpiece interface. Production industries are using difficult to machine materials owing to their improved mechanical properties. Hence it is necessary to improve the productivity of these metals without compromising the quality, time, and cost.

Most of the researchers focused on identifying the effect of process parameters on slide burnishing. Maximov et al. [6] presented the potential of the slide burnishing technique to improve the residual stress, microhardness, and surface finish of aluminum alloys. Korhonen et al. [7] showed an improvement in surface finish, and surface hardness byslide burnishing with an amorphous diamond coated tip on Nitronic-50 HS stainless steel workpiece. Okada et al. [8] introduced a novel method of diamond tip tool, which can be inclined and rotated at the required angle with high speed. Maximov et al. [9] successfully applied slide burnishing on chromium-nickel steels to improve the surface integrity properties such as surface finish, residual stress, microhardness, wear resistance and fatigue strength. Jerez-Mesa et al. [10] investigated the influence of vibration-assisted ball burnishing on the topology of the AISI 1038 specimen. Toboła and Kania [11] investigated the effect of slide burnishing and nitriding phase on the composition and stress state of Sverker 21 and Vanadis 6 steel.Korzynski and Zarski [12] investigated the influence of the stereometric arrangement of AZ91 alloy by slide burnishing and obtained a decent surface finish. Tang et al. [13] carried out cryogenic burnishing on titanium alloy, and it was noticed that the surface finish of the material was enriched after performing cryogenic burnishing. It was claimed that its corrosion resistance had been improved along with the distribution of uniform grains. Pu et al. [14] achieved ultrafine grains structure on $\mathrm{Mg}-\mathrm{Al}-\mathrm{Zn}$ alloy after cryogenic burnishing. It was concluded that the united influence of strong basal texture and grain refinement is the reason for the enhanced corrosion resistance of the material. Yang et al. [15] inspected the influence of severe plastic deformation in the burnishing of $\mathrm{Co}-\mathrm{Cr}-\mathrm{Mo}$ biomaterial and proved that the proper selection of the process parameters yields improved surface integrity in the cryogenic environment. Pu et al. [16] reported the impact of cryogenic burnishing on AZ31B Mg alloy, and it was noticed that surface hardness, the corrosion resistance of the material were improved because of grain refinement by cryogenic burnishing.

Slide burnishing performance indices are significantly gets affected by the input parameters. Hence there is a need to develop a correlation model between these two. One of the most commonly used statistical techniques is the Response Surface Methodology (RSM). Genetic Algorithm (GA) is also one of the broadly used techniques which is a computer-based search algorithm and is the most suitable in optimizing different functions. GA is known to be an effective tool in locating global optima with multiple runs. Hassan et al. [17] established a correlation model between process parameters and surface roughness by RSM. El-Axir et al. [18] designed the experiments using RSM with central composite design (CCD) to investigate the surface finish of the 2014 aluminum alloy using ball burnishing technique. El-Taweel and Ebied [19] developed a unique method to increase microhardness and reduce roundness error in roller burnishing and the optimum process parameters in burnishing were achieved by the RSM method. El-Khabeery and El-Axir [20] explored the optimal process parameters of the burnishing on the base of RSM with CCD. Maximov et al. [21] performed the optimization of the process parameters in diamond burnishing of $41 \mathrm{Cr} 4$ steel under different criteria. Santhanakrishnan et al. [22] studied the constraints of the machine in analyzing the temperature rise using GA. Liu and Wang [23] have optimized the milling process parameters by modified GA. The performance was improved by the successful implementation of the modified GA. Surface roughness reduction $[24,25]$, minimizing burr height during the drilling process of steel alloys [26], titanium alloy machining [27] are the common instances where GA was successfully implemented in industries.

The literature survey reveals that researchers have worked on different optimization methods to optimize the slide burnishing process parameters on geometric characterization and performance estimation independently. Few of them have tried to optimize the process parameters of the slide burnishing at varying lubrication conditions. 17-4 PH stainless steel is an emerging material in numerous fields because of its admirable properties. Hence it is necessary to develop a correlation model and analyze its performance in the slide burnishing under the cryogenic cooling condition. So far only a few research works have been reported on modeling and optimization of process parameters of the slide burnishing under cryogenic environment using RSM and multi-objective genetic algorithm (MOGA) $[18,26,34]$. The present research work is focused on the multi objective optimization of the process parameters by considering minimum surface roughness, maximum surface hardness criteria and modelling of the process factors during slide burnishing of 17-4 PH stainless steel under the cryogenic condition by using a novel slide burnishing tool. Optimization has been carried out by using MOGA and modeling has been performed by RSM. The outline of the article is as follows: Sect. 2 explains the experimental setup, and novel tool. Results and discussions of experimentation, the influence of the process parameters on the output response, modeling and optimization were elucidated in Sect. 3 . The conclusions of the present work were drawn in Sect. 4. 


\section{Material and methods}

\subsection{Investigational technique and material}

'Kirloskar' lathe was used to burnish the 17-4 PH stainless steel. The experimental system is as demonstrated in Fig. 1. The slide burnished surface finish depends on the preliminary surface finish of the sample before the slide burnishing [31, 32]. Hence the turning process has been performed to remove a layer of the material using tungsten carbide insert to minimize surface cracks which affect the slide burnishing performance [28]. The average surface roughness and surface hardness before diamond burnishing were found to be $1.15 \mu \mathrm{m}$ and $342 \mathrm{HV}$ respectively. Theslide burnishing experiments have been carried out at different levels and process parameters, experimental details of which are tabulated in Table 1 and Table 2 respectively. Based on the literature survey on the slide burnishing process and the set of trial experiments carried out on the 17-4 PH stainless steel workpiece, the set of control variables and their levels have been carefully chosen. The experiments were carried out by considering the RSM based face-centered CCD. The software used for designing the experiment is Design Expert 10.0, and Table 3 tabulates the experimental results attained during the study.The true replicates used in the present study were 6 . No randomization was carried out in the experimental tests.

\subsection{Measurement and cryogenic set up}

An external jet cooling cryogenic setup was used to perform the experiments. 'TA55' tank has been used to store the liquid nitrogen $\left(\mathrm{LN}_{2}\right)$. The $\mathrm{LN}_{2}$ inside the tank was compressed by supplying the compressed air at a pressure of $0.3 \mathrm{MPa}$ using $1 \mathrm{HP}$ compressor. A nozzle having a

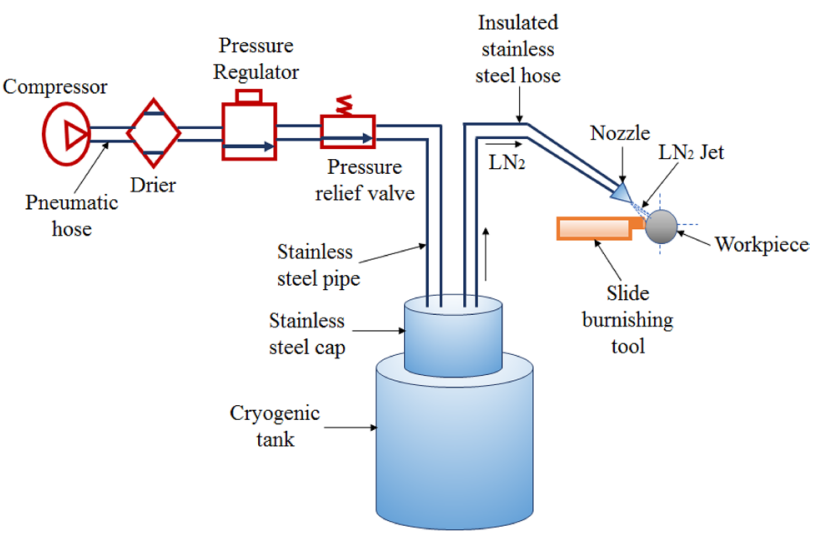

Fig. 1 Schematic of cryogenic diamond burnishing
Table 1 Control variables and their levels

\begin{tabular}{lllll}
\hline Burnishing process parameters & \multicolumn{3}{l}{ Levels } \\
\cline { 3 - 5 } & & 1 & 2 & 3 \\
\hline Burnishing speed $(\mathrm{v})$ & $\mathrm{m} / \mathrm{min}$ & 21 & 67 & 113 \\
Burnishing feed $(\mathrm{f})$ & $\mathrm{mm} / \mathrm{rev}$ & 0.048 & 0.072 & 0.096 \\
Burnishing force $(\mathrm{t})$ & $\mathrm{N}$ & 50 & 125 & 200
\end{tabular}

diameter of $2 \mathrm{~mm}$ was used to supply the $\mathrm{LN}_{2}$ at the toolwork interface, and the flow rate was kept stable at $0.36 \mathrm{l} /$ min. To supply $L N_{2}$ from the tank to the nozzle, stainless steel hose has been used.

SJ301 Mitutoyo Surftest was used to measure the surface finish. The surface roughness tester consists of a stylus tip of a radius $2 \mu \mathrm{m}$. A force of $0.75 \mathrm{mN}$ was applied to measure the surface roughness of the specimen. The stylus speed was maintained to be constant at $0.25 \mathrm{~mm} / \mathrm{sec}$. The cut off length of $4 \mathrm{~mm}$ was considered. In the present study "Ra" parameter was analyzed as a measure of surface roughness. An average of six measurements on each slide burnished surface were considered for calculating the "Ra" value.

Vickers hardness machine 'VM-120' was used to record the surface hardness. A dwell time of $15 \mathrm{~s}$ and an indentation load of $30 \mathrm{kgf}$ was used to measure the surface hardness of the specimen. An average of six readings was considered for the surface hardness measurement.

\subsection{Novel tool}

Figure 2 depicts a novel slide burnishing tool that was used to carry out the experiments. From the extensive literature review and author's experience, it was observed that to improve the performance of the slide burnishing tool it is important to incorporate few modifications in the slide burnishing tool which is readily available in the global market.To overcome a few issues, we faced while

Table 2 Experimental details [8]

\begin{tabular}{|c|c|c|}
\hline \multirow{2}{*}{$\begin{array}{l}\text { Workpiece material and dimensions } \\
\text { Chemical composition of 17-4 PH SS }\end{array}$} & \multicolumn{2}{|c|}{$\begin{array}{l}17-4 \mathrm{PH} \text { stain- } \\
\text { less steel } \\
\text { round bar of } \varnothing \\
30 \mathrm{~mm} \times 150 \mathrm{~mm}\end{array}$} \\
\hline & $\mathrm{Ni}$ & $4.62 \%$ \\
\hline & $\mathrm{Cr}$ & $18.53 \%$ \\
\hline & $\mathrm{Cu}$ & $2.96 \%$ \\
\hline & $\mathrm{Si}$ & $0.07 \%$ \\
\hline & $C$ & $6.03 \%$ \\
\hline & $P$ & $0.51 \%$ \\
\hline & $\mathrm{Fe}$ & Balance \\
\hline
\end{tabular}


Table 3 Experimental results attained for RSM design

\begin{tabular}{lclcll}
\hline SI. No & $\begin{array}{l}\text { Burnishing speed } \\
(\mathrm{m} / \mathrm{min})\end{array}$ & $\begin{array}{l}\text { Burnishing feed } \\
(\mathrm{mm} / \mathrm{rev})\end{array}$ & $\begin{array}{l}\text { Burnishing } \\
\text { force }(\mathrm{N})\end{array}$ & $\begin{array}{l}\text { Surface rough- } \\
\text { ness }(\mu \mathrm{m})\end{array}$ & $\begin{array}{l}\text { Surface } \\
\text { hardness } \\
(\mathrm{HV})\end{array}$ \\
\hline 1 & 67 & 0.072 & 125 & 0.09 & 368 \\
2 & 113 & 0.096 & 50 & 0.25 & 352 \\
3 & 113 & 0.048 & 50 & 0.25 & 360 \\
4 & 67 & 0.048 & 125 & 0.11 & 380 \\
5 & 21 & 0.096 & 50 & 0.45 & 351 \\
6 & 67 & 0.096 & 125 & 0.09 & 360 \\
7 & 67 & 0.072 & 200 & 0.13 & 385 \\
8 & 113 & 0.048 & 200 & 0.25 & 372 \\
9 & 21 & 0.048 & 50 & 0.29 & 374 \\
10 & 113 & 0.096 & 200 & 0.23 & 355 \\
11 & 67 & 0.072 & 125 & 0.06 & 365 \\
12 & 113 & 0.072 & 125 & 0.11 & 360 \\
13 & 21 & 0.096 & 125 & 0.33 & 395 \\
14 & 67 & 0.072 & 125 & 0.06 & 370 \\
15 & 67 & 0.072 & 125 & 0.06 & 369 \\
16 & 21 & 0.048 & 125 & 0.24 & 417 \\
17 & 67 & 0.072 & 0.07 & 366 \\
18 & 67 & 0.072 & 0.072 & 0.03 & 364 \\
19 & 21 & 0.072 & 0.13 & 382 \\
20 & 67 & & 125 & &
\end{tabular}

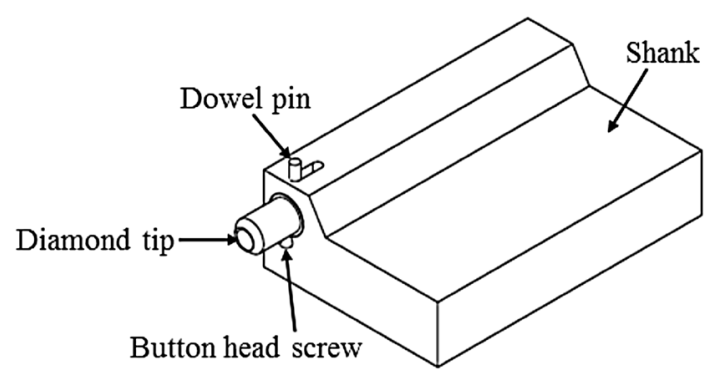

Fig. 2 A novel slide burnishing tool

using a readily available tool, a novel slide burnishing tool was designed and fabricated which is as shown in Fig. 2 to conduct experiments on the material under consideration. It consists of the shank, diamond tip, button head screw, and stem as major parts. A heavy-duty spring was located in the shank which has been connected to the stem of the tool. It absorbs most of the vibration-induced on the machine while burnishing. The required amount of burnishing force has been applied by compressing the spring against the workpiece. The movement of the spring has been calibrated and measured by using a dowel pin which was also positioned on the shank. The spring deflection was noted using a dial gauge. The shank of the tool has been specially designed with a smaller overhang in order to place it conveniently on any conventional or
CNC machining centers. In the present study, a $4.5 \mathrm{~mm}$ radius spherical diamond tip was used to carry out the slide burnishing.

\section{Results and discussion}

The analysis and development of a quadratic model for surface hardness and surface roughness have been carried out. Most of the researchers have used Q-Q plots to test the assumption of normality. It is said that if the predicted value behaves linearly along with the observed value then the data is said to be normally distributed and it is true in the case of both surface roughness and surface hardness, in this work.

\subsection{Influence of control factors on surface roughness}

To distinguish the effect of factors on the performance characteristicsthe perturbation plot is used. The perturbation graph obtained for the surface roughness is framed in Fig. 3. Identical results were noticed from the interaction of variables plot as depicted in Figs. 4, 5 and 6 . The influence of burnishing speed on the surface finish is represented in Figs. 4 and 5 . It can be observed that the surface finish declines to the least 


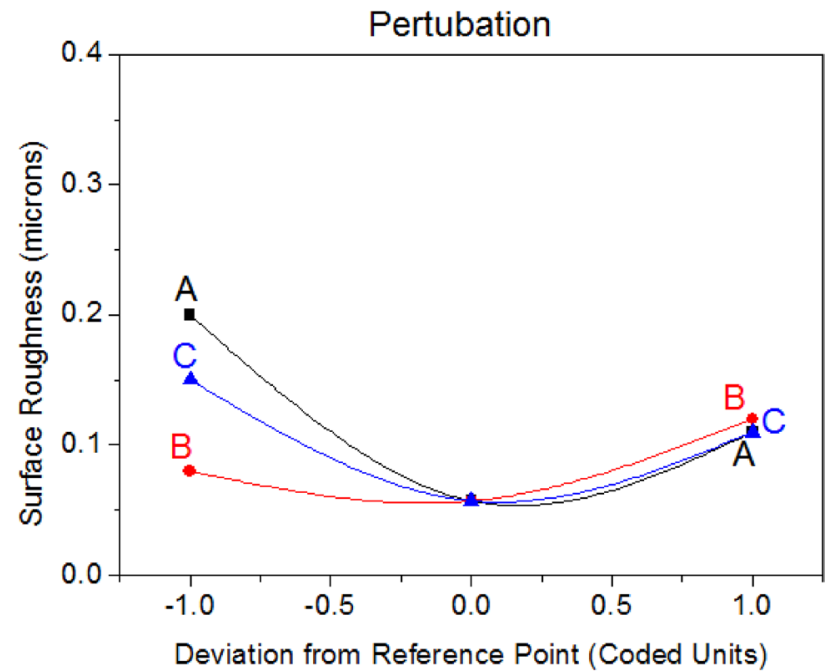

Fig. 3 Perturbation plot for surface roughness

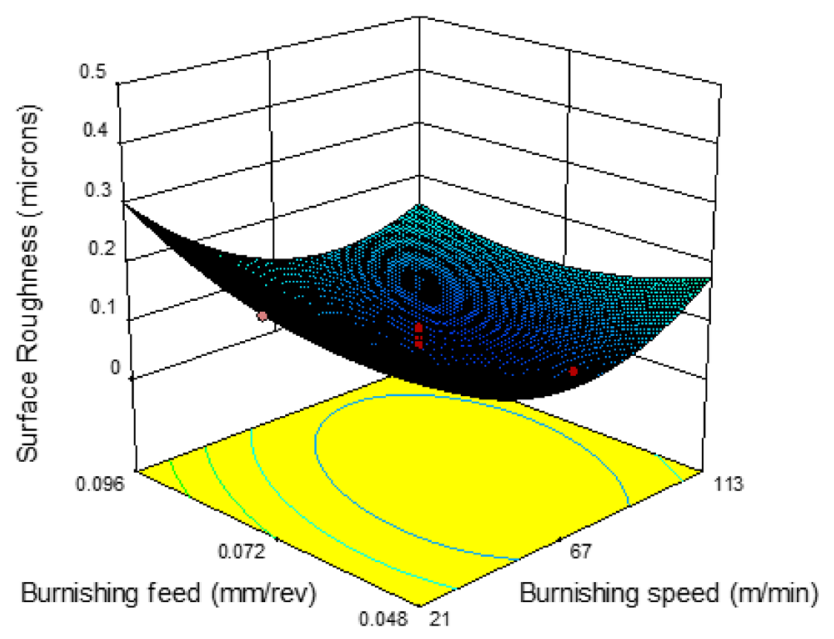

Fig. 4 Analysis of surface roughness based on the interaction influence of burnishing feed and burnishing speed

value while increasing the burnishing speed. If the speed was increased further way beyond this limit a sudden increase in the surface roughness has been observed. Primarily, the initial decrement in this output parameter was observed since the diamond tip had further chances and time to push the irregularities into the valleys. The presence of chatter during burnishing also leads to increased surface roughness at the higher specified burnishing speed $[19,20,32]$. Figures 4 and 6 depict the variation of surface finish with varying burnishing feed. A similar trend that was observed for burnishing speed has been repeated for burnishing feed. It can be observed that surface roughness declines to the least value while increasing the burnishing feed. If the feed was increased further way beyond this limit a sudden

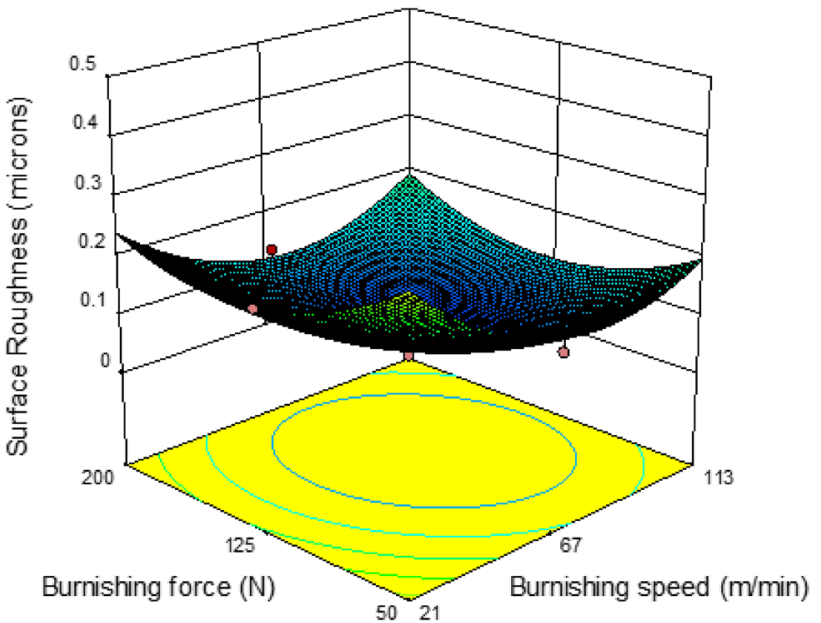

Fig. 5 Analysis of surface roughness with respect to the interaction effect of burnishing speed and burnishing force

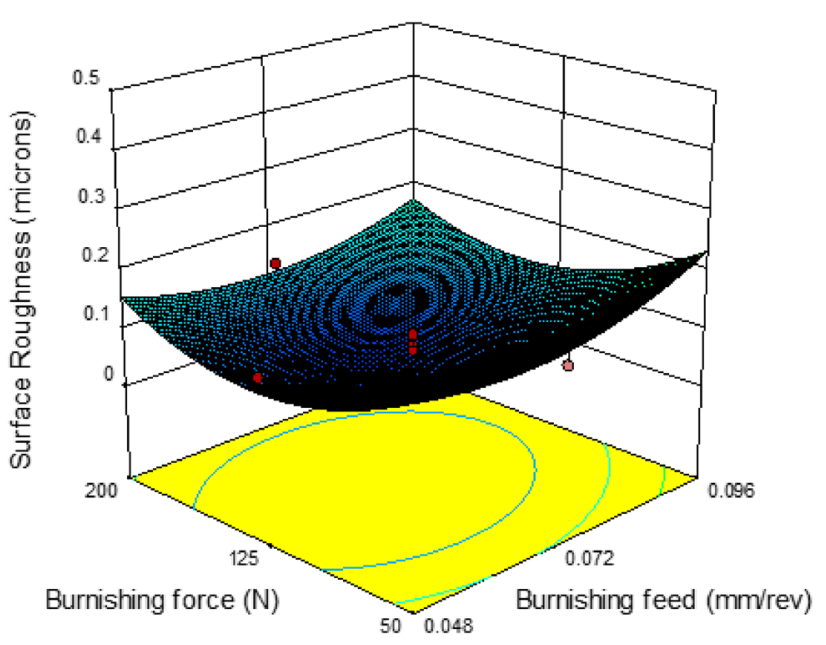

Fig. 6 Analysis of surface roughness on the basis of interaction impact of burnishing force and burnishing feed

increase in the surface roughness has been noticed. It is because the gap amongst the successive traces of the tool tip is small at lower feed and at higher feed more gap will be available among the successive traces of the tool which causes a sudden increase in the surface roughness of the specimen $[29,30]$. The results of the slide burnishing process will be affected by the variation of burnishing force as depicted in Figs. 5 and 6. At the middle range of the burnishing force, minimum surface roughness was obtained. Whereas at the initial and final set of burnishing force the surface roughness attained was high [31]. It is due to the fact that higher burnishing forces lead to shear failure on the subsurface of the 
specimen and flaking is also another major reason which has to be pointed out for obtaining this trend [32, 33].

\subsection{Analysis of surface roughness}

A quadratic model has been developed for surface roughness. The regression model coefficient is represented in Eq. (1).

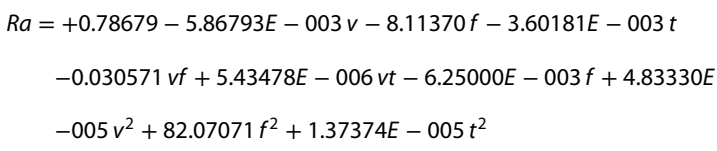

Analysis of variance (ANOVA) was used to analyze the adequacy and significance of the regression model coefficient. The results observed are tabulated in Table 4. The significance of the model can be tested based on the value of " $P>F$ " which should be always less than 0.05 . If " $P<0.0001$ " then all the terms in the model have a significant effect on the performance characteristics. Due to noise, the chances of getting a large $F$ value might be $0.01 \%$. The significance of the terms in the model is tested based on " $P>F$ " which should be is less than 0.0500 . The terms in the model are said to be insignificant if its value is greater than 0.1000. Based on these conditions, $t^{2}, v$, $v f, t, v^{2}, f$, and $f^{2}$ are observed to be significant terms. The insignificant terms which are present in the model can be reduced to obtain improved results. From the "Lack of Fit F-value" of 2.07, it can be observed that "lack of fit" is insignificant. Due to noise, only $22.14 \%$ chances are available to obtain large "Lack of Fit F-value". Insignificant lack of fit is necessary to fit the model and a similar result has been obtained in the study which is charted in Table 4.

To find the adequacy of the model, supplementary checks have to be performed. The coefficient of determination $\left(R^{2}\right)$ and inspection of residuals are the two most important factors which are to be measured. It is believed that $R^{2}$ should have a range between one and zero. The difference between the predicted and attained performance characteristics will lead to the determination of residuals. This could be possibly attained by the plot of residuals and predicted vs. actual responses. The adequacy of the model can be identified by 2 methods. The first one being, a straight line should be obtained in the normal probability chart. The second method is an obvious pattern that should not be produced in the predicted versus actual responses chart. Figures 7 and 8 prove that the errors are distributed normally along the straight line which has been formed by the residuals points and it doesn't produce an obvious pattern respectively. Therefore, it is concluded from the above results that the achieved model is an adequate model for predicting the surface finish of the sample since it fulfills all the conditions which are required for an adequate model. Table 4 represents that "Pred R-Squared" is in good agreement with "Adj R-Squared." The variation noticed was below 0.2. "Adeq Precision" yields the value of the $S / N$ ratio which will be considered desirable if its ratio is beyond 4. The model's overall performance was indicated by Pred R-Squared which also shows how well the statistical model is fixed to the data. Predicted R-Squared of $84 \%$ from the ANOVA results for surface roughness proves that experimental data fit the
Table 4 ANOVA for surface roughness

\begin{tabular}{|c|c|c|c|c|c|c|c|}
\hline Source & Sum of squares & df & Mean square & $F$ value & Cont $\%$ & $p$ value prob $>F$ & \\
\hline Model & 0.23 & 9 & 0.026 & 44.21 & & $<0.0001$ & Significant \\
\hline v & 0.018 & 1 & 0.018 & 30.48 & 7.50 & 0.0003 & \\
\hline$f$ & $4.410 E-003$ & 1 & $4.410 \mathrm{E}-003$ & 7.62 & 1.84 & 0.0201 & \\
\hline $\mathrm{t}$ & $3.610 E-003$ & 1 & $3.610 E-003$ & 6.24 & 1.50 & 0.0316 & \\
\hline vf & $9.113 E-003$ & 1 & $9.113 E-003$ & 15.75 & 3.80 & 0.0027 & \\
\hline $\mathrm{vt}$ & $2.813 E-003$ & 1 & $2.813 E-003$ & 4.86 & 1.17 & 0.0520 & \\
\hline $\mathrm{ft}$ & $1.012 E-003$ & 1 & $1.012 \mathrm{E}-003$ & 1.75 & 0.42 & 0.2154 & \\
\hline$v^{2}$ & 0.029 & 1 & 0.029 & 49.70 & 12.10 & $<0.0001$ & \\
\hline$f^{2}$ & $6.145 E-003$ & 1 & $6.145 E-003$ & 10.62 & 2.56 & 0.0086 & \\
\hline$t^{2}$ & 0.016 & 1 & 0.016 & 28.37 & 6.67 & 0.0003 & \\
\hline Residual & $5.787 E-003$ & 10 & $5.787 \mathrm{E}-004$ & & & & \\
\hline Lack of Fit & $3.904 \mathrm{E}-003$ & 5 & $7.807 E-004$ & 2.07 & & 0.2214 & Not significant \\
\hline Pure error & $1.883 \mathrm{E}-003$ & 5 & $3.767 \mathrm{E}-004$ & & & & \\
\hline Cor total & 0.24 & 19 & & & & & \\
\hline Std. dev & 0.024 & & R-squared & 0.9755 & & & \\
\hline Mean & 0.17 & & Adj R-squared & 0.9534 & & & \\
\hline C.V.\% & 14.03 & & Pred R-squared & 0.8447 & & & \\
\hline Press & 0.037 & & Adeq precision & 21.902 & & & \\
\hline
\end{tabular}




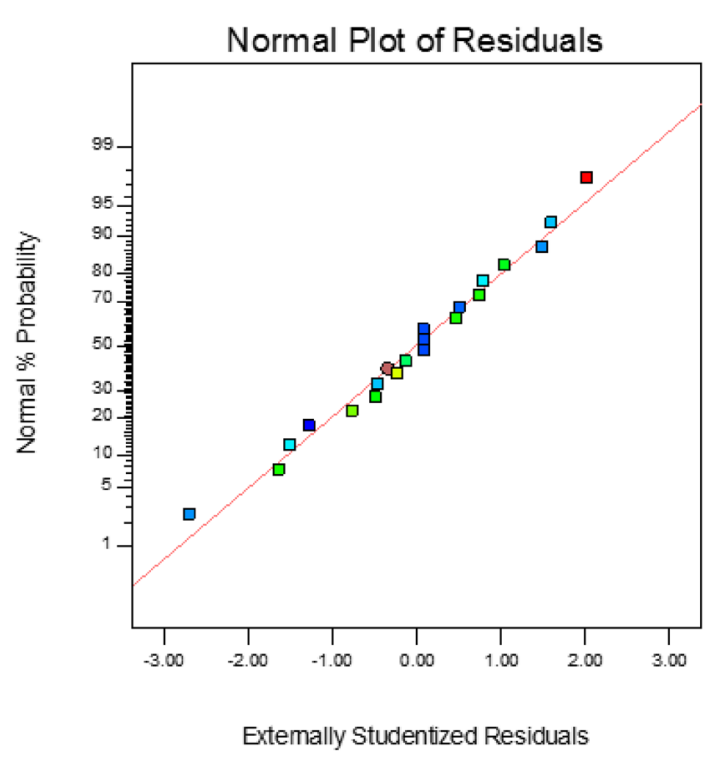

Fig. 7 Normal probability plot for surface roughness

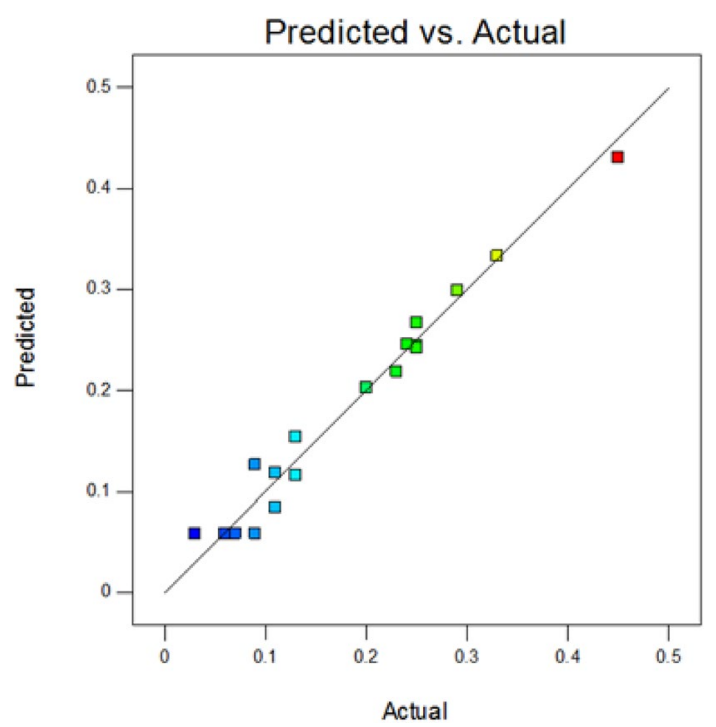

Fig. 8 Predicted versus actual plot for surface roughness

model reasonably well. The model is found to be adequate from the ratio of 21.902. Figure 9 illustrates the predicted and navigational results. The outcome of the predicted and residuals results fits well. The correlation among the residuals and the trials has been framed in Fig. 10. It was seen that a random scatter was observed without a proper trend. The cube plot framed in Fig. 11 signifies the optimal setting of the control variables to obtain the minimum surface finish of the specimen which is located at the right corner. At the corner of the cube, the minimum surface roughness of $0.218659 \mu \mathrm{m}$ was noticed for a burnishing

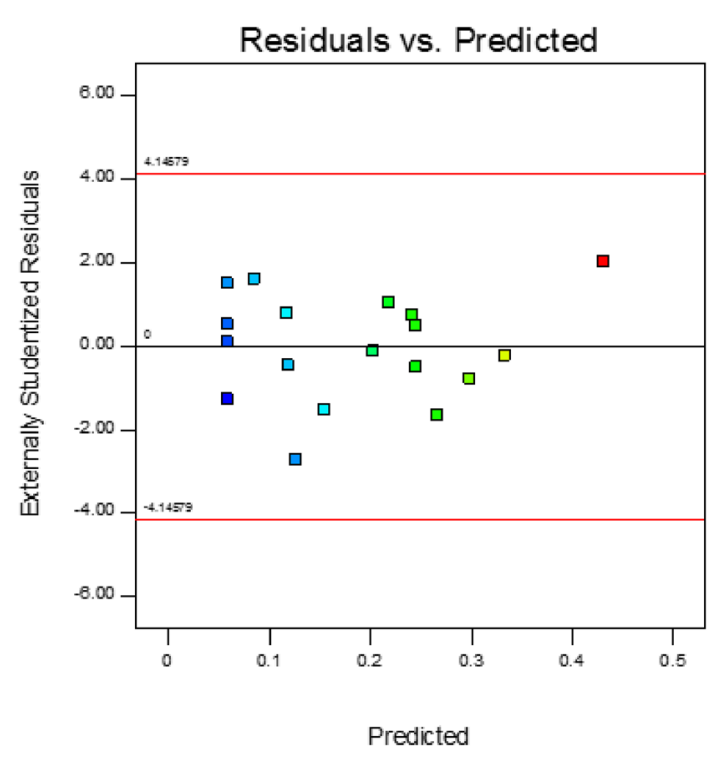

Fig. 9 Residuals vs. predicted graph for surface roughness

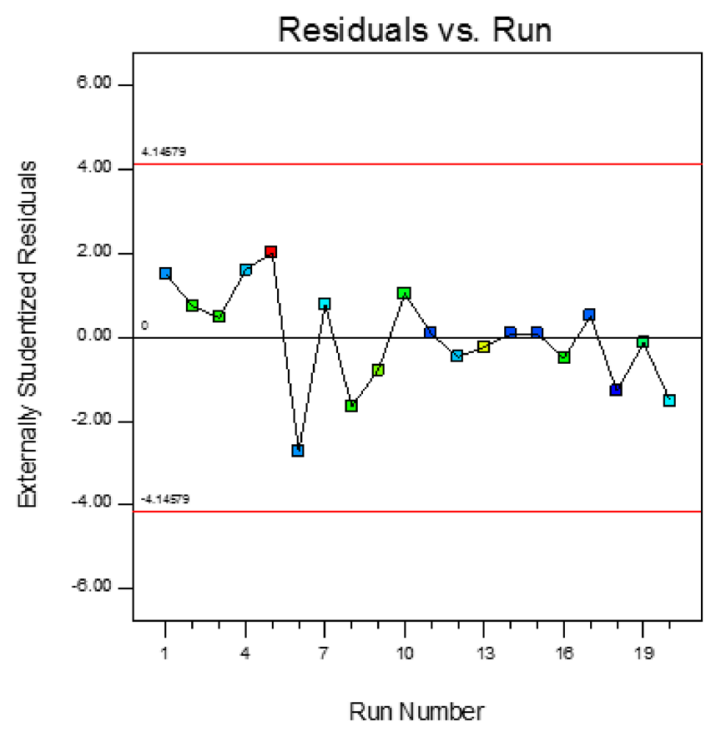

Fig. 10 Residuals vs. experimental run graph for surface roughness

force of $200 \mathrm{~N}$, a burnishing feed of $0.096 \mathrm{~mm} / \mathrm{rev}$, and a burnishing speed of $113 \mathrm{~m} / \mathrm{min}$.

\subsection{Influence of control factors on surface hardness}

The perturbation graph illustrated in Fig. 12 demonstrates the trend of surface hardness obtained for different factors used in the present study. A comparable effect was found in the 3D plot for all the variables which is presented in Figs. 13, 14 and 15. It was noticed that the parameters have their own interaction impact on the surface hardness. The effect of burnishing speed on the surface hardness is 


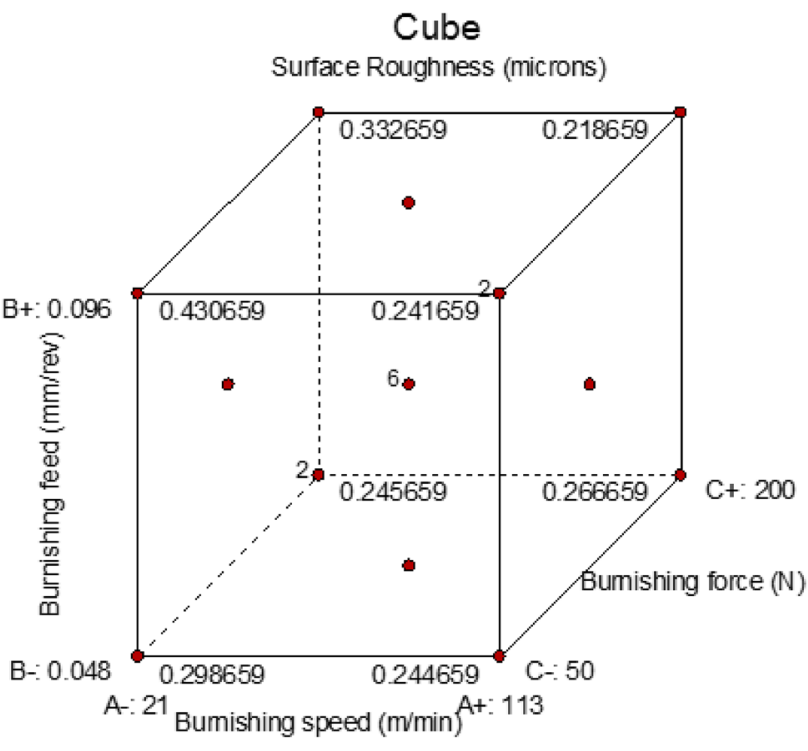

Fig. 11 Cube plot for surface roughness

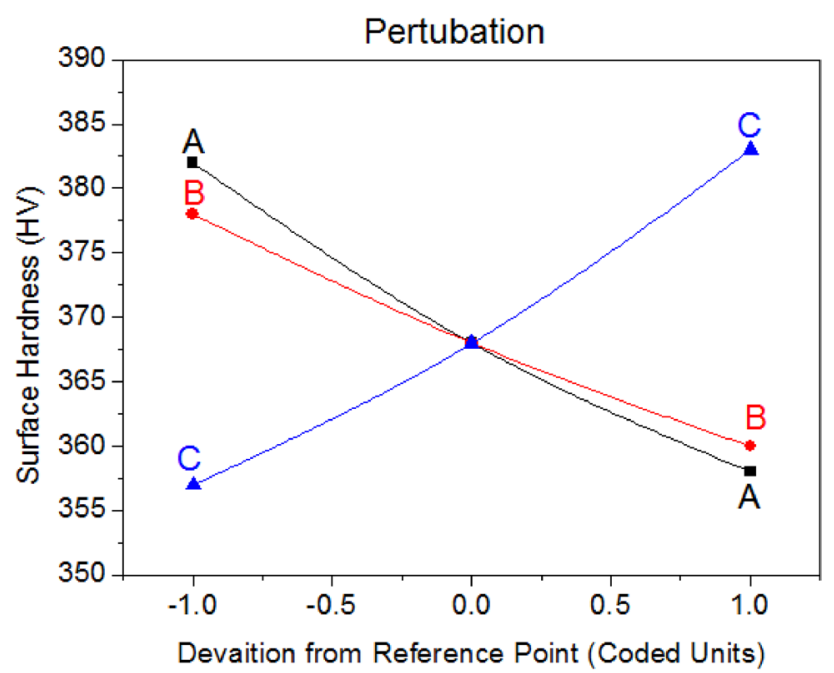

Fig. 12 Perturbation plot for surface hardness

portrayed in Figs. 13 and 14. It was seen that the decreasing surface hardness trend was observed for increasing burnishing speed. It is owing to the inducement of chatter while the tool slides over the surface of the workpiece. Especially while working at higher burnishing speed the chatter experienced was high [33]. The surface hardness variation with varying burnishing feed is framed in Figs. 13 and 15. Every increment in the burnishing feed has resulted in the reduction of the surface hardness. At lower burnishing feed the overlap of the sliding tool tip over the workpiece surface was observed to be more which was induced by the plastic deformation [34]. Hence at lower burnishing feed maximum surface hardness was attained.

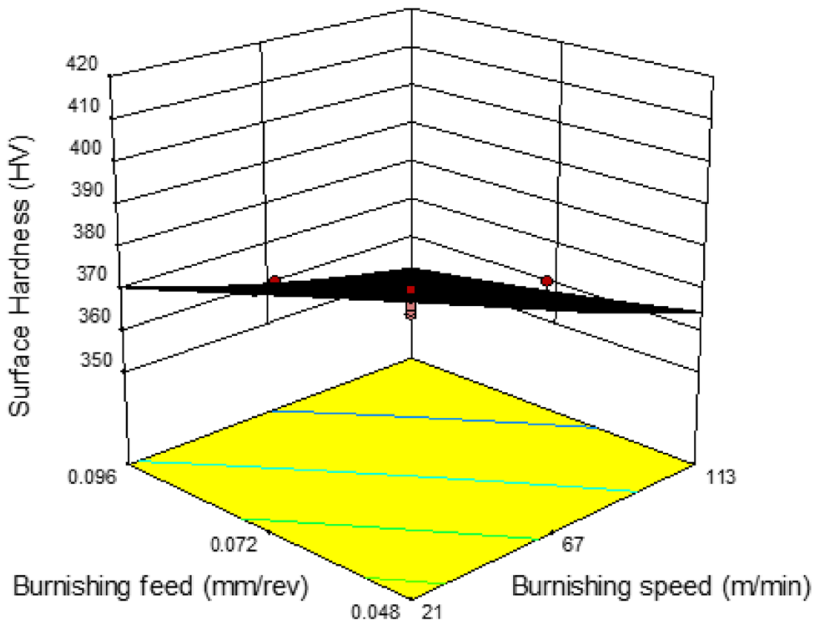

Fig. 13 Interaction influence of burnishing feed and burnishing speed on surface hardness

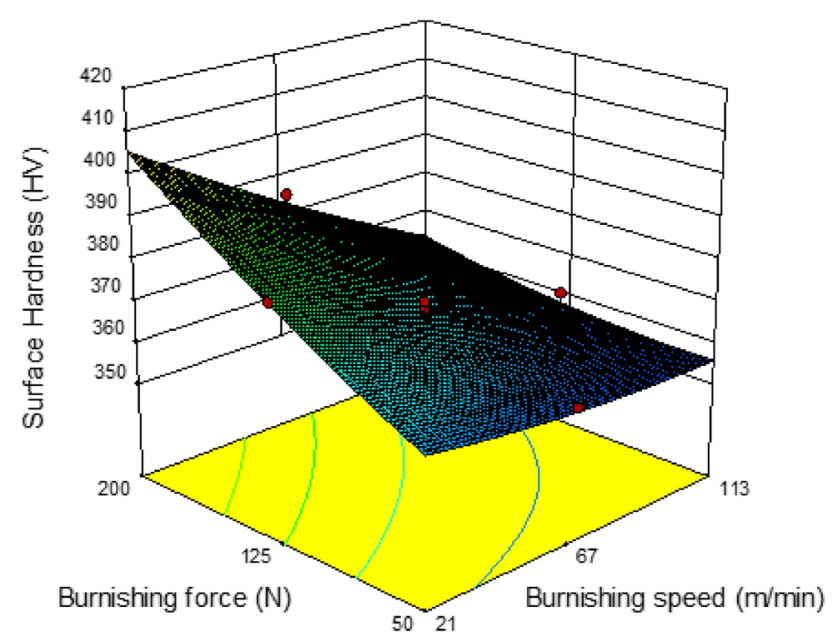

Fig. 14 Interaction influence of burnishing force and burnishing speed on surface hardness

For the enhancement of surface hardness of the material, burnishing force is treated to be one of the vital control parameters, and the influence of it on surface hardness is denoted in Figs. 14 and 15. It can be observed that the surface hardness was increasing when the burnishing force was varied from minimum to maximum value. That's because as the tool passes on the surface, the surface deformation increases. This is the reason for work hardening which has been generated because of the repeated plastic deformation [35, 36].

Overall from the surface hardness analysis, it was observed that the cryogenic slide burnishing process can improve the surface hardness of the material. Due to the constant spraying of the $\mathrm{LN}_{2}$ at the burnishing zone, the temperature generated will be reduced. Another reason 
for the improvement of surface hardness may be claimed due to the strain hardening effect observed because of the use of cryogenic coolant, and the material becomes stronger and harder during the working condition due to the splashing of the $\mathrm{LN}_{2}$ at the tool-workpiece interface. The grain refinement takes place just beneath the top surface layer of the slide burnished specimen due to the combination of impingement of the $\mathrm{LN}_{2}$ at the burnishing zone and severe plastic deformation of the material taking place as a reason of the slide burnishing process $[13,14]$.

\subsection{Analysis of surface hardness}

Similar to the surface roughness, the regression equation obtained for surface hardness is as follows:

$$
\begin{array}{r}
H=+390.13289-0.20145 v-616.36748 f+0.29183 t+2.26449 v f-2.60870 E \\
-003 v t-0.55556 f+7.73329 E-004 v^{2}+1104.79798 f^{2}+3.79798 E-004 t^{2}
\end{array}
$$

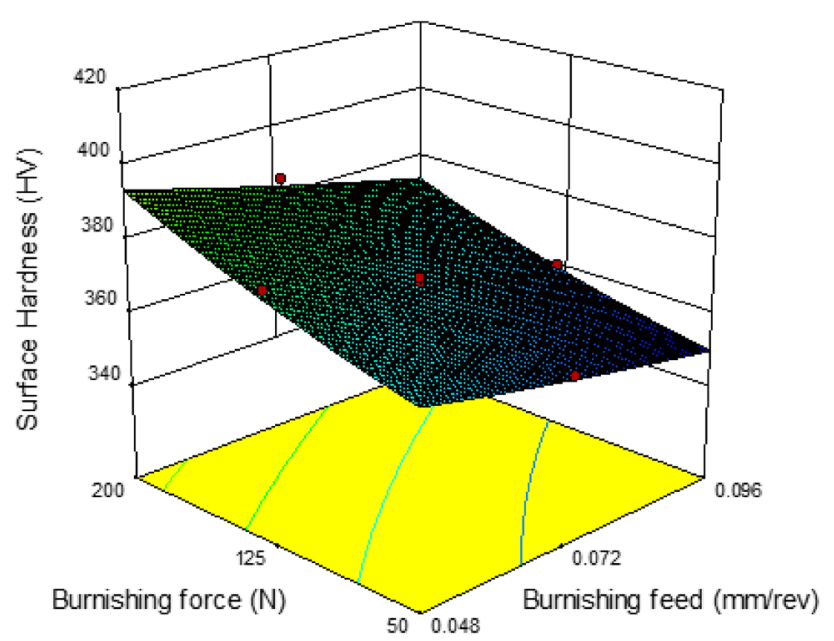

Fig. 15 Interaction influence of burnishing force and burnishing feed on surface hardness
The ANOVA results attained for surface hardness are tabulated in Table 5. It was observed that the developed model is significant. Insignificant lack of fit is good to fit a model and a similar result was attained for surface hardness. The significance of the model was proved by the $F$ value of 80.44 . "Prob $>F$ " which is less than 0.0500 represents the terms in the model are significant. The significant terms were identified to be $\mathrm{v}, \mathrm{f}, \mathrm{t}, \mathrm{vf}$, vt. The terms which are $>0.1000$ are known to be insignificant. If the insignificant model terms are reduced then the possibility of improvement in the model is high. The lack of fit $F$-value $=1.32$ illustrates that it is insignificant in contrast with the pure error. The variation which could be observed due to noise is $38.54 \%$. "Pred R-Squared"of 0.9052 and "Adj R-Squared" of 0.9741 prove that both are in sensible agreement among each other with a difference of 0.2 . Also, Predicted R-Squared is considered as a measure of
Table 5 ANOVA for surface

\begin{tabular}{|c|c|c|c|c|c|c|c|}
\hline Source & Sum of squares & $\mathrm{df}$ & Mean square & F value & Cont \% & $p$ value prob $>F$ & \\
\hline Model & 4693.71 & 9 & 521.52 & 80.44 & & $<0.0001$ & Significant \\
\hline v & 1440.00 & 1 & 1440.00 & 222.10 & 30.26 & $<0.0001$ & \\
\hline$f$ & 810.00 & 1 & 810.00 & 124.93 & 17.02 & $<0.0001$ & \\
\hline $\mathrm{t}$ & 1664.10 & 1 & 1664.10 & 256.66 & 34.97 & $<0.0001$ & \\
\hline vf & 50.00 & 1 & 50.00 & 7.71 & 1.05 & 0.0196 & \\
\hline $\mathrm{vt}$ & 648.00 & 1 & 648.00 & 99.94 & 13.61 & $<0.0001$ & \\
\hline $\mathrm{ft}$ & 8.00 & 1 & 8.00 & 1.23 & 0.17 & 0.2926 & \\
\hline$v^{2}$ & 7.36 & 1 & 7.36 & 1.14 & 0.15 & 0.3116 & \\
\hline$f^{2}$ & 1.11 & 1 & 1.11 & 0.17 & 0.02 & 0.6873 & \\
\hline$t^{2}$ & 12.55 & 1 & 12.55 & 1.94 & 0.26 & 0.1943 & \\
\hline Residual & 64.84 & 10 & 6.48 & & & & \\
\hline Lack of fit & 36.84 & 5 & 7.37 & 1.32 & & 0.3854 & $\begin{array}{l}\text { Not signifi- } \\
\text { cant }\end{array}$ \\
\hline Pure error & 28.00 & 5 & 5.60 & & & & \\
\hline Cor total & 4758.55 & 19 & & & & & \\
\hline Std. dev & 2.55 & & R-squared & 0.9864 & & & \\
\hline Mean & 370.15 & & Adj R-squared & 0.9741 & & & \\
\hline C.V.\% & 0.69 & & Pred R-squared & 0.9052 & & & \\
\hline Press & 451.01 & & Adeq precision & 37.656 & & & \\
\hline
\end{tabular}
hardness 


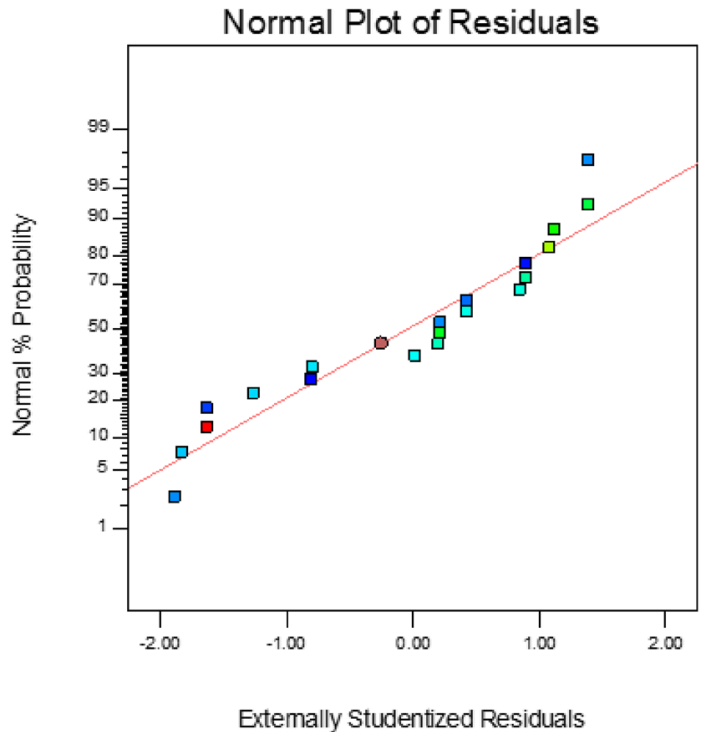

Fig. 16 Normal probability plot for surface hardness

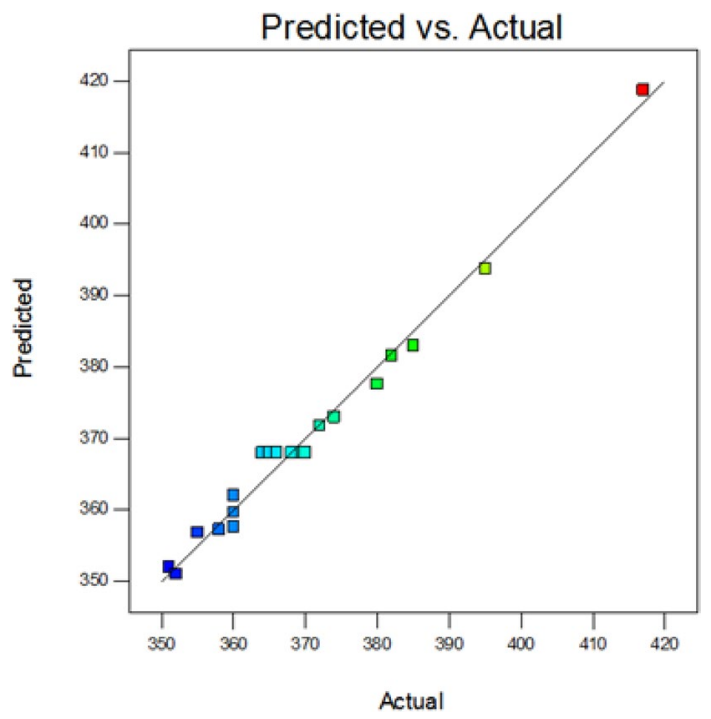

Fig. 17 Predicted versus actual plot for surface hardness

the model's overall performance, indicating how well the statistical model is fixed to the data. The results for surface hardness presented in the ANOVA showed that the experimental data fits the model reasonably well with Predicted R-Squared of $90 \%$. It has been observed that the signal is adequate with "Adeq Precision" ratio of 37.656.

Figures 16 and 17 illustrated the normal graph of residuals and predicted versus actual graph for surface hardness. A similar methodology to surface roughness analysis has been followed to analyze the above-mentioned plots. Figures 16 and 17 prove that the errors are distributed normally along the straight line which has been formed

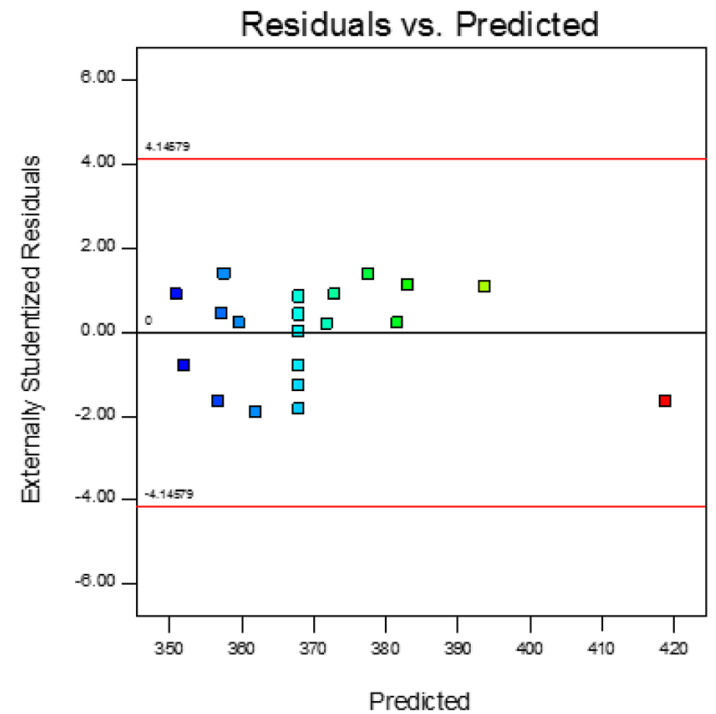

Fig. 18 Residuals vs. predicted graph for surface hardness

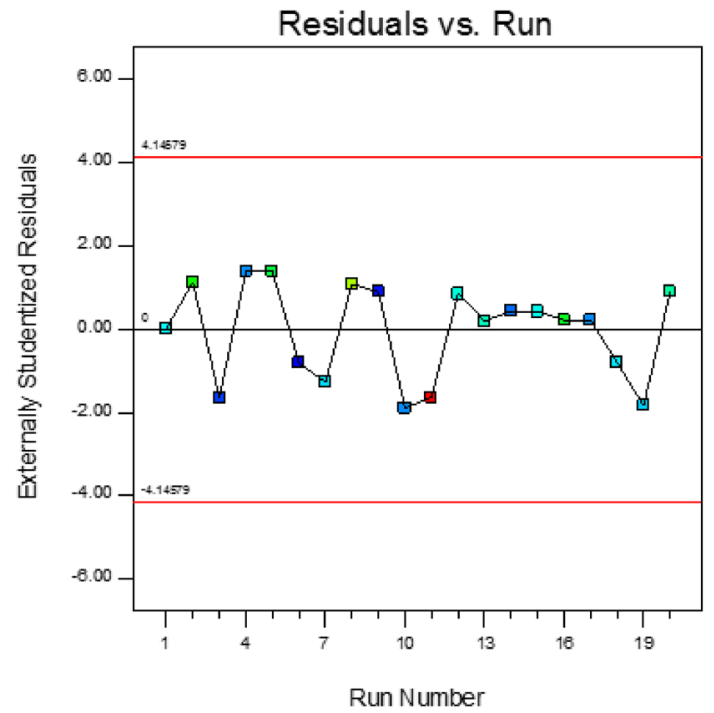

Fig. 19 Residuals vs. experimental run graph for surface hardness

by the residuals points and it doesn't produce an obvious pattern respectively. Therefore, it can be concluded that the model is adequate and significant. Figure 18 depicts the predicted and experimental results which also evidences that the model fits well. It is apparent that the residuals and predicted outcomes fits well. The correlation among the residuals and the trials has been framed in Fig. 19. It was seen that a random scatter was observed without a proper trend. Figure 20 depicts the cube plot obtained for the surface hardness. The maximum surface hardness obtained is located at the bottom left corner of the cube for the optimal process parameters. For burnishing force $=200 \mathrm{~N}$, burnishing feed $=0.096 \mathrm{~mm} / \mathrm{rev}$, 


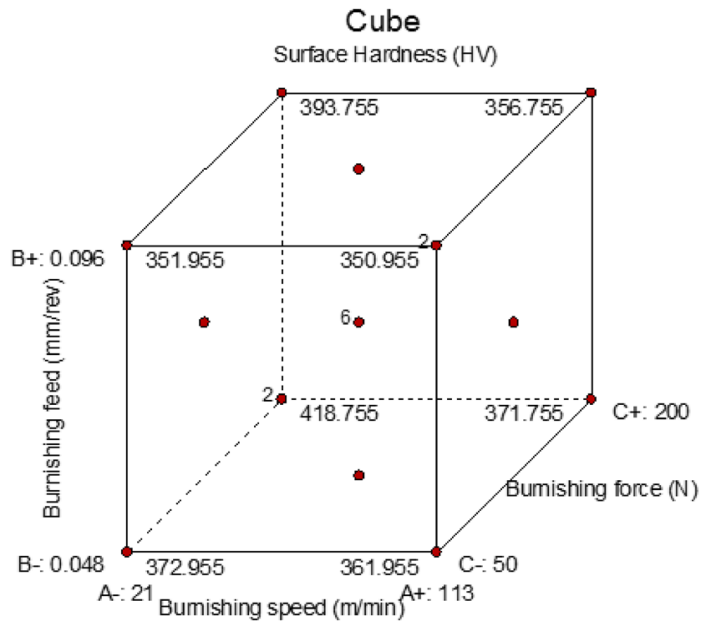

Fig. 20 Cube plot for surface hardness

and burnishing speed $=21 \mathrm{~m} / \mathrm{min}$ the surface hardness recorded at the corner of the cube was $418.755 \mathrm{HV}$.

\subsection{Optimization of the process parameters}

$\mathrm{GA}$ is a basic tool that works on the principle of natural selection and genetics. The constrained and unconstrained problems can be solved by this method to get the optimal solution [37]. Chromosomes are the initial set of a solution with which the process starts. Mutation, reproduction, and crossover are the genetic operators on which the convergence depends. To select good strings, the process starts with a step called reproduction. The function of crossover is to split and combine one half of each chromosome with the other pair. The flipping of chromosomes is done by mutation. After this step GA makes use of the individuals at random from the current population called children and parentsfor the next generation [38]. An optimal solution to the population will be achieved from this generation. The best fitness criteria are achieved by repeating the same process. The regression Eqs. (1) and (2) are used as an objective function for attaining the optimal solution.The results were attained for the two performance characteristics. The optimal results were achieved by conducting the trial and error method. MOGA in the Matlab optimization toolbox has been used to try different slide burnishing conditions and to achieve the best outcomes. The set of process parameters considered to perform MOGA are tabulated in Table 6. For all different combinations of operators and iteration, MOGA produces a different result. On the basis of the priority of the performance characteristics, the most appropriate result will be chosen. To obtain the best possible result equal priority has
Table 6 MOGA parameters

\begin{tabular}{ll}
\hline Variables & Values \\
\hline Population size & 50 \\
Crossover fraction & 0.8 \\
Mutation function & Adaptive fea- \\
& sible \\
Iteration & 500
\end{tabular}

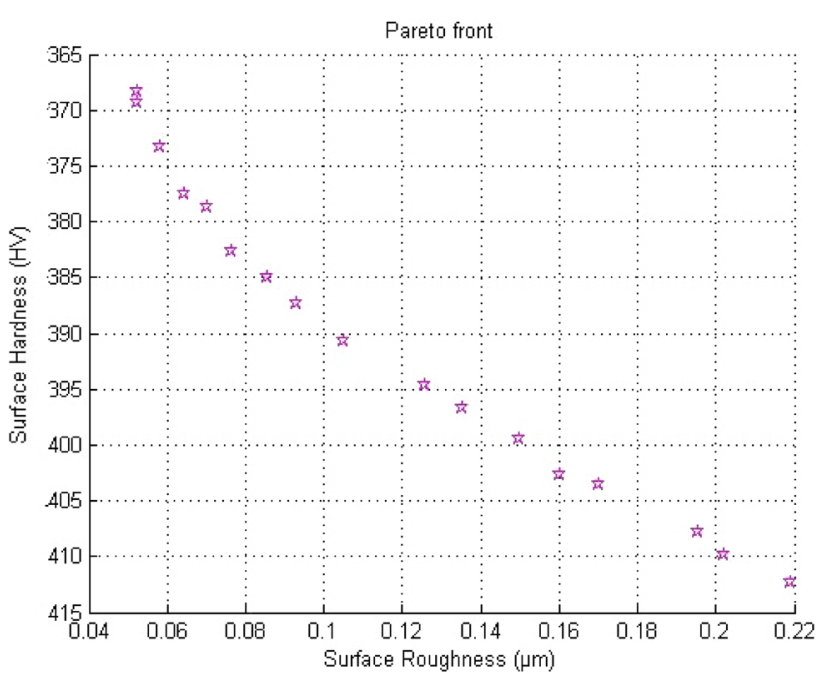

Fig. 21 Plot of Pareto front obtained using MOGA

Table 7 Confirmation results

\begin{tabular}{lll}
\hline Responses & \multicolumn{2}{l}{ Optimal factors } \\
\cline { 2 - 3 } & $\begin{array}{l}\text { Burnishing speed }=74 \mathrm{~m} / \mathrm{min} \\
\text { Burnishing feed }=0.068 \mathrm{~mm} / \\
\text { rev }\end{array}$ \\
\cline { 2 - 3 } & Burnishing force $=132 \mathrm{~N}$ \\
\cline { 2 - 3 } & MOGA & $\begin{array}{l}\text { Confir- } \\
\text { mation } \\
\text { test }\end{array}$ \\
\hline Surface roughness $(\mu \mathrm{m})$ & 0.05 & $\begin{array}{l}0.04 \\
\text { Surface hardness }(\mathrm{HV})\end{array}$ \\
\hline
\end{tabular}

been given for both the output responses. Pareto plot yields the best feasible solution for the combination of performance characteristics which is framed in Fig. 21. From the previous discussion of RSM, the effect of control factors on each response was analyzed separately. In MOGA, the influence of control factors was analyzed by performing multiobjective optimization of the performance characteristics simultaneously. The optimal control factors were found to be burnishing force $=132 \mathrm{~N}$, burnishing feed $=0.068 \mathrm{~mm} / \mathrm{rev}$, and burnishing speed $=74 \mathrm{~m} / \mathrm{min}$. From Table 7 it can be perceived that 
by the effective utilization of MOGA the corresponding best solution attained for surface roughness and surface hardness are $0.05 \mu \mathrm{m}$ and $368 \mathrm{HV}$ respectively.

\subsection{Confirmation test}

With the aim of validating the accuracy of the outcomes obtained by using MOGA, a confirmation test has been performed, and the outcomes are charted in Table 7. Trials were repeated six times to ensure accuracy, and the average reading was considered to be the final value. A negligible deviation was observed between MOGA and experimental findings. It was achieved because of the appropriate selection of MOGA control variables. It is noteworthy from previous works and present study that proper selection of MOGA process parameters play an important role to achieve minimum deviation. It was inferred that the results obtained are within the allowable limit. It has been proved that by the effective implementation of MOGA it is possible to attain the best possibleresult for both the performance characteristics at the optimal control factors. The reduction in surface roughness was observed to be $33 \%$, and similarly, surface hardness enhancement of $2 \%$ was recorded at the optimal control variables in contrast with the initial values of surface roughness and hardness after slide burnishing in the cryogenic environment.

\section{Conclusions}

The present study details the influence of control factors on the cryogenic slide burnishing process. The study focuses more on outcomes such as surface roughness and surface hardness. MOGA was used to find optimal solutions against minimum surface roughness and maximum surface hardness. The surface roughness declines to the least value with an increase in burnishing speed, burnishing feed, and burnishing force. Further increase in these parameters increases surface roughness. At low burnishing feed, low burnishing speed, and high burnishing force maximum surface hardness was noticed. The best combination of the responses was achieved by employing the optimal combination of control factors which has been derived from the model. The adequacy of the model is at 95\% confidence level because a significant "lack of fit" was not found in the quadratic model. The obtained model is adequate and accurate for predicting the outcomes for cryogenic slide burnishing using a novel slide burnishing tool. The optimal control factors obtained from MOGA were burnishing feed of $0.068 \mathrm{~mm} / \mathrm{rev}$, the burnishing force of $132 \mathrm{~N}$, and burnishing speed of $74 \mathrm{~m} / \mathrm{min}$ which yielded the surface hardness of $368 \mathrm{HV}$ and surface roughness of $0.05 \mu \mathrm{m}$. The accuracy of the result was validated by the confirmation experiment. The surface roughness of $0.04 \mu \mathrm{m}$ and surface hardness of $370 \mathrm{HV}$ observed was well within the acceptable limits.

\section{Compliance with ethical standards}

Conflict of interest The authors declare that they have no conflict of interest.

Open Access This article is licensed under a Creative Commons Attribution 4.0 International License, which permits use, sharing, adaptation, distribution and reproduction in any medium or format, as long as you give appropriate credit to the original author(s) and the source, provide a link to the Creative Commons licence, and indicate if changes were made. The images or other third party material in this article are included in the article's Creative Commons licence, unless indicated otherwise in a credit line to the material. If material is not included in the article's Creative Commons licence and your intended use is not permitted by statutory regulation or exceeds the permitted use, you will need to obtain permission directly from the copyright holder. To view a copy of this licence, visit http://creativecommons .org/licenses/by/4.0/.

\section{References}

1. Rao CM, Rao SS, Herbert MA (2019) Studies on the effect of process parameters in turning of Ti-6Al-4V alloy using topsis. In: IOP conference series: materials science and engineering, Vol 577. IOP Publishing, p 012069

2. Rao CM, Rao SS, Herbert MA (2020) An experimental and numerical approach to study the performance of modified perforated cutting tools on machining of Ti-6Al-4V alloy. Arab J Sci Eng 45(2):1191-1206

3. Rao CM, Rao SS, Herbert MA (2018) Influence of modified cutting inserts in machining of Ti-6Al-4V alloy using PCD insert. Mater Today Proc 5:18426-18432. https://doi.org/10.1016/J.MATPR .2018.06.183

4. Charitha R, Shrikantha R, Mervin H (2018) Performance improvement studies for cutting tools with perforated surface in turning of titanium alloy. In: MATEC web of conferences, Vol 144. EDP Sciences, p 03003

5. Sachin B, Narendranath S, Chakradhar D (2018) Effect of cryogenic diamond burnishing on residual stress and microhardness of 17-4 PH stainless steel. Mater Today Proc 5:18393-18399. https://doi.org/10.1016/j.matpr.2018.06.179

6. Maximov JT, Anchev AP, Duncheva GV, Ganev N, Selimov KF (2017) Influence of the process parameters on the surface roughness, micro-hardness, and residual stresses in slide burnishing of high-strength aluminum alloys. J Braz Soc Mech Sci Eng 39(8):3067-3078. https://doi.org/10.1007/s4043 0-016-0647-y

7. Korhonen H, Laakkonen J, Hakala J, Lappalainen R (2013) Improvements in the surface characteristics of stainless steel workpieces by burnishing with an amorphous diamond-coated tip. Mach Sci Technol 17:593-610. https://doi.org/10.1080/10910 344.2013.837351

8. Okada M, Shinya M, Matsubara H, Kozuka H, Tachiya H, Asakawa $\mathrm{N}$, Otsu M (2017) Journal of materials processing technology development and characterization of diamond tip burnishing with a rotary tool. J Mater Process Tech 244:106-115. https://doi. org/10.1016/j.jmatprotec.2017.01.020 
9. Maximov JT, Duncheva GV, Anchev AP, Ganev N, Amudjev IM, Dunchev VP (2018) Effect of slide burnishing method on the surface integrity of AISI 316Ti chromium-nickelsteel. J Braz Soc Mech Sci Eng. https://doi.org/10.1007/s40430-018-1135-3

10. Jerez-mesa R, Landon Y, Travieso-rodriguez JA, Dessein G, Llumafuentes J (2018) Surface and coatings technology topological surface integrity modi fi cation of AISI 1038 alloyafter vibration-assisted ball burnishing. Surf Coat Technol 349:364-377. https://doi.org/10.1016/j.surfcoat.2018.05.061

11. Toboła D, Kania B (2018) Phase composition and stress state in the surface layers ofburnished and gas nitrided Sverker 21 and Vanadis 6 tool steels. Surf Coat Technol 353:105-115. https:// doi.org/10.1016/j.surfcoat.2018.08.055

12. Korzynski M, Zarski T (2016) Slide diamond burnishing influence on of surface stereometric structure of an AZ91 alloy. Surf Coat Technol 307:590-595. https://doi.org/10.1016/j.surfc oat.2016.09.045

13. Tang J, Luo HY, Zhang YB (2016) Enhancing the surface integrity and corrosion resistance of Ti-6Al-4V titanium alloy through cryogenic burnishing. Int J Adv Manuf Technol. https://doi. org/10.1007/s00170-016-9000-y

14. Pu Z, Yang S, Song GL, Dillon OW, Puleo DA, Jawahir IS (2011) Ultrafine-grained surface layer on $\mathrm{Mg}-\mathrm{Al}-\mathrm{Zn}$ alloy produced by cryogenic burnishing for enhanced corrosion resistance. Scr Mater 65:520-523. https://doi.org/10.1016/j.scriptamat .2011.06.013

15. Yang S, Umbrello D, Dillon OW, Puleo DA, Jawahir IS (2015) Cryogenic cooling effect on surface and subsurface microstructural modifications in burnishing of $\mathrm{Co}-\mathrm{Cr}$-Mo biomaterial. J Mater Process Technol 217:211-221. https://doi.org/10.1016/j.jmatp rotec.2014.11.004

16. Pu Z, Song GL, Yang S, Outeiro JC, Dillon OW, Puleo DA, Jawahir IS (2012) Grain refined and basal textured surface produced by burnishing for improved corrosion performance of AZ31B Mg alloy. Corros Sci 57:192-201. https://doi.org/10.1016/j.corsc i.2011.12.018

17. Hassan AM, Al-Jalu HF, Ebied AA (1998) Burnishing force and number of ball passes for the optimum surface finish of brass components. J Mater Process Technol 83:176-179. https://doi. org/10.1016/S0924-0136(98)00058-2

18. El-Axir MH, Othman OM, Abodiena AM (2008) Study on the inner surface finishing of aluminum alloy 2014 by ball burnishing process. J Mater Process Technol 202:435-442. https://doi. org/10.1016/j.jmatprotec.2007.10.040

19. El-Taweel TA, Ebeid SJ (2009) Effect of hybrid electrochemical smoothing-roller burnishing process parameters on roundness error and micro-hardness. Int J Adv Manuf Technol 42:643-655. https://doi.org/10.1007/s00170-008-1632-0

20. El-Khabeery MM, El-Axir MH (2001) Experimental techniques for studying the effects of milling roller-burnishing parameters on surface integrity. AEJ Alex Eng J 40:355-365

21. Maximov JT, Duncheva GV, Anchev AP et al (2020) Smoothing, deep, or mixed diamond burnishing of low-alloy steel components-optimization procedures. Int J Adv Manuf Technol 106:1917-1929. https://doi.org/10.1007/s00170-019-04747-2

22. Santhanakrishnan M, Sivasakthivel PS, Sudhakaran R (2017) Modeling of geometrical and machining parameters on temperature rise while machining Al 6351 using response surface methodology and genetic algorithm. J Braz Soc Mech Sci Eng 39:487-496. https://doi.org/10.1007/s40430-015-0378-5

23. Liu Y, Wang C (1999) Modified genetic algorithm based optimization of milling parameters. Int J Adv Manuf Technol 15:796799. https://doi.org/10.1007/s001700050134
24. Kilickap E, Huseyinoglu M, Yardimeden A (2011) Optimization of drilling parameters on surface roughness in drilling of AISI 1045 using response surface methodology and genetic algorithm. Int J Adv Manuf Technol 52:79-88. https://doi.org/10.1007/s0017 0-010-2710-7

25. Mahesh G, Muthu S, Devadasan SR (2015) Prediction of surface roughness of end milling operation using genetic algorithm. Int J Adv Manuf Technol 77:369-381. https://doi.org/10.1007/s0017 0-014-6425-z

26. Kilickap E, Huseyinoglu M (2010) Selection of optimum drilling parameters on burr height using response surface methodology and genetic algorithm in drilling of AISI 304 stainless steel. Mater Manuf Process 25:1068-1076. https://doi.org/10.1080/10426 911003720854

27. Çolak O (2014) Optimization of machining performance in highpressure assisted turning of Ti6Al4V alloy. Stroj Vestnik J Mech Eng 60:675-681. https://doi.org/10.5545/sv-jme.2013.1079

28. Sachin B, Narendranath S, Chakradhar D (2020) Application of desirability approach to optimize the control factors in cryogenic diamond burnishing. Arab J Sci Eng 45:1-13

29. Sachin B, Narendranath S, Chakradhar D (2019) Enhancement of surface integrity by cryogenic diamond burnishing toward the improved functional performance of the components. J Braz Soc Mech Sci Eng 41(10):396

30. Nemat M, Lyons AC (2000) An investigation of the surface topography of ball burnished mild steel and aluminium. Int J Adv Manuf Technol 16(7):469-473. https://doi.org/10.1007/s0017 00070054

31. Sachin B, Narendranath S, Chakradhar D (2019) Analysis of surface hardness and surface roughness in diamond burnishing of 17-4 PH stainless steel. In: IOP conference series: materials science and engineering, Vol 577, No. 1. IOP Publishing, p 012075

32. El-Taweel TA, El-Axir MH (2009) Analysis and optimization of the ball burnishing process through the taguchi technique. Int J Adv Manuf Technol 41:301-310. https://doi.org/10.1007/s0017 0-008-1485-6

33. El-Axir MH (2000) Investigation into roller burnishing. Int J Mach Tools Manuf 40:1603-1617. https://doi.org/10.1016/S0890 $-6955(00) 00019-5$

34. Sachin B, Narendranath S, Chakradhar D (2018) Experimental evaluation of diamond burnishing for sustainable manufacturing. Mater Res Express 5:106514. https://doi.org/10.1088/20531591/aadb0a

35. Hassan AM, Al-Bsharat AS (1996) Influence of burnishing process on surface roughness, hardness, and microstructure of some non-ferrous metals. Wear 199:1-8. https://doi. org/10.1016/0043-1648(95)06847-3

36. Hassan AM (1997) The effects of ball- and roller-burnishing on the surface roughness and hardness of some non-ferrous metals. J Mater Process Technol 72:385-391. https://doi. org/10.1016/S0924-0136(97)00199-4

37. Abrão AM, Denkena B, Breidenstein B, Mörke T (2014) Surface and subsurface alterations induced by deep rolling of hardened AISI 1060 steel. Prod Eng 8:551-558. https://doi.org/10.1007/ s11740-014-0539-x

38. Leo Kumar SP (2018) Experimental investigations and empirical modeling for optimization of surface roughness and machining time parameters in micro end milling using genetic algorithm. Meas J Int Meas Confed 124:386-394. https://doi.org/10.1016/j. measurement.2018.04.056

Publisher's Note Springer Nature remains neutral with regard to jurisdictional claims in published maps and institutional affiliations. 